\title{
Another route to fusion to be explored
}

US looks hard

at inertial

\section{confinement}

\section{Washington}

The Department of Energy (DoE) is proposing to set up what one official describes as a "bluest of blue ribbon" review committee to look at the prospects of developing inertial-confinement fusion (ICF) techniques as a commercial source of nuclear power.

The decision to take a hard look at ICF comes close on the heels of a new bill signed into law by President Carter two weeks ago pledging support for a substantially expanded programme of research into magnetic confinement fusion, at present the front runner in the fusion race.

The Administration has been persuaded to back the Magnetic Fusion Bill by a report from the DoE's Energy Research Advisory Board. This says that results using magnetic confinement techniques at, for example, Princeton University's Plasma Physics Laboratory, are sufficiently impressive to justify the next stage of the development programme.

The bill proposes setting up a National Magnetic Fusion Engineering Center to look at the technical problems involved in scaling up laboratory experiments. It also requires DoE to produce a five-year programme for magnetic fusion detailing budget and research schedules.

The same committee, chaired by $\mathrm{Dr}$ Solomon Buchsbaum of Bell Laboratories, has now been asked to look at the progress and prospects of ICF. DoE's proposal is contained in a letter from Energy Secretary $\mathrm{Mr}$ Charles Duncan to the Office of Management and Budget, accompanying the department's budget request for the fiscal year 1982 .

Department officials feel that, largely as the result of significant advances made during the past year or so, research on the civilian applications of ICF has progressed sufficiently to make it possible to evaluate the relative merits of different systems now under development.

Research on ICF has also been given a boost by a recent DoE decision to start declassifying previously secret information on high-energy $X$ rays produced by the explosion of deuterium-tritium pellets the source of fusion energy.

Three weeks ago, the department reported that it had decided that the following statement should no longer be considered a military secret: "In some ICF targets, radiation from the conversion of focused energy (such as laser or particle beam) can be contained and used to transfer energy to compress and ignite a physically separate component containing nuclear fuel".

DoE officials play down the impact of classification on the civilian programme, insisting that this has not prevented its own scientists from weighing the relative merits of different approaches. University scientists, however, have long argued that classification has been a barrier to their research; designs for ion drivers, for example, have required access to details of pellet behaviour in order to optimize beam/pellet interaction. "This is the news we have been waiting for"', said one person on hearing DoE's decision.

The main problem now facing the ICF research community is how to choose the best technology for moving on to the logical next stage, the construction of a facility to probe the engineering difficulties that may lie ahead.

There is a general consensus that for magnetic fusion the Russian Tokamak design is still clearly the front-runner, but several options remain for the drivers needed to produce the energy that ignites the pellet for ICF. These include gas lasers, glass lasers and particle accelerators using light and heavy ions.

For the medium term, the best prospects seem to lie with either glass lasers or lightion accelerators. Support for the former, in particular, has been increased by recent results from the University of Rochester, demonstrating that halving the wavelength of the light produces an ultraviolet laser beam that interacts much more efficiently

with the pellet than does an infrared laser

Dr Moshe Lubin, director of Rochester's Laser Energetic Laboratory, said last week that it was now possible to reach an efficiency of at least 80 per cent in converting the wavelength of the laser beam. This raises the possibility that crucial scaling-up experiments could be carried out much sooner than expected.

Further ahead, both glass lasers and light ions could face major difficulties. The lasers are difficult to cool, and it might therefore be hard to achieve tha high repetition rates necessary for the largescale production of power. Light ions, although effective at close range, are difficult to focus accurately.

Here, two other options may come into their own - krypton fluoride lasers, now being developed at the University of California's Lawrence Livermore Laboratory, and heavy-ion beams, at present being squeezed for funding by a congressional preference for glass lasers with potential military applications, but eagerly supported by nuclear physicists as an extension of particle accelerator research.

DoE officials are more sceptical, suggesting that some of the claims of nuclear physicists have been overoptimistic and partly motivated by interlaboratory competition for funds. Nevertheless, they admit that heavy ions are a serious contender for eventual commercialization, and hope that the new review committee will throw some light on where research priorities should lie.

David Dickson

\section{Canada's uranium with strings attached}

There is a prospect of a dispute between Canada and Euratom over uranium supplies. Canada is prepared to stop uranium supplies to Europe if Euratom states fail to comply with Canadian nonproliferation policy. But Euratom "is not going to surrender", according to Euratom and Canadian officials.

The confrontation will come to a head later this year, when an interim arrangement reached in January 1978 expires. And since Australia is taking a similar stance to that of Canada and the position of the United States - the other potentially large uranium supplier in the 1980 s and 1990 s is clouded by the 1978 Non-Proliferation Act, uranium supply negotiations are becoming an increasingly sensitive element in the future growth of nuclear power.

Australia is furthest ahead in its negotiations with Europe. West Germany has a major share in the new Ranger mine, which will give the country 20,000 tonnes of uranium oxide in 1982-86 according to a recent agreement with the Australian government - provided Australia secures satisfactory non-proliferation agreements with Euratom. (Euratom currently negotiates safeguards with suppliers for its nine members, and must "approve" any bilateral supply deals. But its supranational authority is under strong challenge from France - a further complication.

France also has a draft deal with Australia for the supply of 2,000 tonnes of uranium a year - a fifth of its estimated need in 1990 - but again that awaits an agreement between Australia and Euratom. The draft deal itself includes outline safeguards arrangements; but both sides have dodged giving them firm interpretation. Australia, mindful of the strong anti-nuclear lobby at home, has a public commitment (as does Canada) to ensure that none of its uranium is used for weapons building; so its policy is to require "prior consent" for re-transfers of its uranium outside Euratom states, for reprocessing and for enrichment beyond 20 